\title{
Sterols from Jatropha tanjorensis leaves exhibit anti-inflammatory potential: in vitro and in silico studies
}

\author{
Damilola Alex Omoboyowa* ${ }^{*}$
}

\begin{abstract}
Background: Inflammation has continued to raise global challenges and Jatropha tanrogenesis (JT) is used traditionally for its management. In this study, the in silico and in vitro anti-inflammatory potential of bioactive sterols were investigated. The active compounds of ethanol extract of JT leaves were identified using Gas chromatography-mass spectrometry (GC.MS) followed by molecular docking against COX-1 and COX-2 using maestro Schrödinger and pharmacokinetic profile prediction using webserver tools. The in vitro anti-inflammatory and anti-oxidantive potentials were investigated using standard protocols.

Results: GC-MS analysis of ethanol extract of JT leaves revealed the presence of eight (8) compounds, the molecular docking analysis of these compounds demonstrated varying degrees of binding affinities against the target proteins. The extract exhibit concentration dependent anti-oxidant activity with $\mathrm{IC}_{50}$ of 106.383 and $6.00 \mathrm{Fe}^{2+} \mathrm{E} / \mathrm{g}$ for DPPH and FRAP respectively. The extract showed significant $(P<0.05)$ reduction in percentage inhibition of hemolysis at $200 \mu \mathrm{g} /$ $\mathrm{ml}$ while non-significant $(P>0.05)$ increase was observed at 600 and $1000 \mu \mathrm{g} / \mathrm{ml}$ compared to $200 \mu \mathrm{g} / \mathrm{ml}$ of diclofenac sodium. At lower concentration of 25 and $50 \mu \mathrm{g} / \mathrm{ml}$, percentage inhibition of albumin denaturation was significantly $(P<0.05)$ higher compared to $200 \mu \mathrm{g} / \mathrm{ml}$ of diclofenac sodium. Drug likeness prediction and ADME/toxicity screening showed that the bioactive compounds possess no side effects.
\end{abstract}

Conclusion: The results obtained in this study suggested that, JT leaves possess anti-inflammatory activity and could be used as a source of new drug.

Keywords: Anti-inflammatory, Anti-oxidant, In silico, In vitro, Cyclooxygenase

\section{Background}

Inflammation is the natural response of body's immune system triggered by noxious stimulus and conditions such as pathogens, cellular damage and irritants that occurs in vascular tissues (Bouhlali et al. 2016). The major aim of inflammatory response is to localize and eliminate the harmful agents and remove damaged tissue components (Oguntibeju 2018). Acute inflammatory reactions reduce damage and infections, also involve in the restoration of homeostasis within the tissue (Nathan and Ding 2010).

*Correspondence: damilola.omoboyowa@aaua.edu.ng

Department of Biochemistry, Adekunle Ajasin University, Akungba-Akoko, Ondo State, Nigeria
However, uncontrolled inflammatory responses may result in chronic inflammation which has been implicated in many inflammatory diseases (Akinloye et al. 2020). Inflammation and oxidation are related since oxidants that damage cells result into inflammation (Yesmin et al. 2020). Free radicals are natural by-products, which are constantly produced in vivo for specific metabolic purposes such as signal transduction, gene expression and activation of receptors. Excessive production of free radicals leads to inflammation (Yesmin et al. 2020).

The available non-steroidal anti-inflammatory drugs (NSAIDs) act by blocking the cyclooxygenase (COX) enzyme, reducing the release of prostaglandins thereby ameliorating pains and inflammation. Two COX isoforms 
have been studied with different pattern of expressions (Akinloye et al. 2020). NSAIDs selectively inhibits COX-1 and reduce inflammation with associated side effects such as gastrointerstinal tract (GIT) damage and ulcer while COX-2 induced by pro-inflammatory cytokines without GIT disorders (Williams et al. 1999). Hence, natural compounds of plant origin may serve as drugs that are COX-2 selective as anti-inflammatory agents.

The use of natural products as drug candidate has been attributed to their phytochemical constituents (Erukainure et al. 2018) and their anti-inflammatory efficacy has been observed to surpass synthetic drugs (Attiq et al. 2018). Jatropha tanjorensis (Ellis and Saroja) is a perennial herb that belongs to the family Euphrobiaceae, it is an exotic plant in Nigeria and native of America (Olayiwola et al. 2004). The plant is commonly known as catholic vegetable, the Yoruba speaking tribe of South-western Nigeria called the plant Lapalapa or iyana ipaja (Ochulor et al. 2018).

J. tanjorensis leaf has been reported to possess hematopoietic activity (Orhue et al. 2008), hypoglycemic and anti-diabetes activity (Olayiwola et al. 2004). The antioxidative potential of $J$. tanjorensis leaves against reactive oxygen species produced in protein energy malnutrition (PEM) has been reported by Omoregie and Osagie (2011). Its anti-arthritic property has also been documented by Arun and Brindha (2012). This study aimed to evaluate the in silico and in vitro anti-inflammatory activities of $J$. tanjorensis leaves and to identify the active compounds.

\section{Methods}

\section{Collection and preparation of plant sample}

Jatropha tanjorensis (JT) leaves were obtained within the metropolis of Okitipupa, Nigeria. The leaves were taxonomically identified and authenticated at the Department of Biological Science, Olusegun Agagu University of Science and Technology (OAUSTECH), Okitipupa, Ondo State, Nigeria. The (OAUSTECH-18008) voucher number was deposited at their herbarium. The leaves were washed and air-dried at room temperature in the laboratory for three weeks, the dried leaves were ground into powdery form.

\section{Preparation of extract}

Exactly $138 \mathrm{~g}$ of powdered JT leaves was soaked in $960 \mathrm{ml}$ ethanol for $72 \mathrm{~h}$ and shaken intermittently. The slurry formed was filtered and the filtrate was dried under pressure with rotary evaporator. The concentrated sample was weighed and extract yield was calculated, the crude extract was stored in the refrigerator until use for GCMS analysis, in vitro antioxidant and anti-inflammatory assays. The extract yield was calculated as:

$$
\text { Extract yield }=\frac{\text { Crude extract }}{\text { Dried Sample }} \times 100
$$

Gas chromatography-mass spectrometry (GC-MS) analysis GC-MS analysis of the ethanol extract was performed using Gas chromatography coupled to a mass detector Turbo mass gold (Perkin- Elmer) spectrometer with an Elute- $5 \mathrm{~ms}$ ( $5 \%$ diphenyl/95\% dimethyl poly siloxane, $30 \mathrm{~m} \times 0.25 \mathrm{~mm} \times 0.25 \mu \mathrm{g} \mathrm{df}$ ) of capillary column as previously described by Okereke et al. (2017). The oven was set to an initial temperature of $110^{\circ} \mathrm{C}$ for 2 min, further increased up to $200{ }^{\circ} \mathrm{C}$ at the rate of $10{ }^{\circ} \mathrm{C} / \mathrm{min}$. finally temperature was raised up to $280{ }^{\circ} \mathrm{C}$, at the rate of $5{ }^{\circ} \mathrm{C} /$ min for $9 \mathrm{~min}$. Helium gas was used as the carrier gas at constant flow rate of $1 \mathrm{ml} / \mathrm{min}$. An aliquot of $2 \mu \mathrm{l}$ of sample was injected into the column with the injector temperature at $250{ }^{\circ} \mathrm{C}$ (spilt ratio of 10:1). The electron ionization system with ionizing energy of $70 \mathrm{eV}$ was used. Mass spectral scan range was set at 45 to $450 \mathrm{~m} / \mathrm{z}$ (Okereke et al. 2017). The National Institute of Standard and Technology (NIST) library database was used in the interpretation of the mass spectrum.

\section{In silico ADME/toxicity screening and drug likeness prediction}

The ADME (absorption, distribution, metabolism, and excretion) and toxicity screening and drug-likeness prediction of the compounds were carried out using admetSAR1.0 prediction online tool (http://lmmd.ecust.edu.cn) (Cheng et al. 2012) and swissADME server (http://www. swissadme.ch) (Daina et al. 2017) respectively to predict the pharmacokinetics and pharmacodynamics profiles of the compounds.

\section{Protein crystal structure and ligands collection}

Eight (8) chemical compounds obtained from GCMS analysis were subjected to molecular docking with selected anti-inflammatory protein targets. These molecular targets include cyclooxygenase-1 (COX-1) and cyclooxygenase-2 (COX-2) with pdb ID: 5U6X and 3NTG respectively retrieved from the protein data bank (http://www.rcsb.org) in 3D format. The existing ligands and water molecules were removed and hydrogen molecules were added during protein preparation. The structure-data file (SDF) structures of the compounds and standard ligands were downloaded from the PubChem database (https://pubchem.ncbi.nlm.nih.gov) (Omoboyowa et al. 2021).

\section{Molecular docking and docking validation}

Molecular docking was performed between the 3D crystallography structure of COX-1 and 2, and the bioactive 
compounds obtained from GC-MS analysis of Jatropha tanrogenesis. The docking protocol was conducted using the default parameters in the Schrodinger suite 2018. The 3D structure of the target proteins were preprocessed by employing Protein preparation Wizard module in the Schrodinger suite 2018 (Sastry et al. 2013). Herein, missing hydrogen atoms and loops were added to the protein while the native co-crystallized ligand and water molecules were deleted from the protein. The protein's electronic polarization and small backbone fluctuations were defined using the standard distance-dependent dielectric constant at $2.0 \AA$ (Balogun et al. 2021). Conjugated gradient procedure was utilized for the subsequent optimization of the proteins and restrained refinement of hydrogen atoms with the maximum root-mean-square deviation (RMSD) at $0.3 \AA$ under optimized potentials for liquid simulations (OPLS)-3 force field (Friesner et al. 2006; Roos et al. 2019).

Similarly, J. tanrogenesis ligands library were obtained from GC-MS analysis and prepared for molecular docking by utilizing the LigPrep tool under default parameters in the Maestro-Schrodinger suite 2018 (Maestro 2018). The binding site of the co-crystalized ligands of each protein was considered for molecular docking pocket of $J$. tanrogenesis ligands library under default parameters by extra precision (XP) protocol of Schrodinger GLIDE tool (Maestro 2018).

Furthermore, the co-crystallized ligand was extracted from the crystal complex, prepared using the above ligand preparation method, and re-docked in the same selective active site in order to validate the docking procedure. A RMSD value of $1.02 \AA$ was obtained $(<2 . \AA)$.

\section{Molecular mechanics/generalized born surface area (MM/ GBSA) calculation}

MM/GBSA calculation, an advanced quantum mechanics calculation that helps remove false-positive obtained from molecular docking analysis was performed to compute the relative binding free energy for each Cyclooxygenase-ligand complex. The Prime MM/GBSA module in the Maestro-Schrodinger suite under default parameters was used (Prime 2018). The mathematical representation of the step to calculate the binding free energy was represented by the equation below.

$$
\Delta G^{\text {bind }}=G^{\text {complex }}-\left(G^{\text {protein }}+G^{\text {ligand }}\right)
$$

\section{In vitro anti-inflammatory analysis}

The Hypotonicity-induced haemolysis and inhibition of albumin denaturation of ethanol extract of Jatropha tanjorensis leaves were carried out according to the methods described by Leelaprakash and Mohan-Dass (2011) and Azeem et al. (2010) respectively.

\section{In vitro antioxidant assays}

The 1,1 diphenyl-2-picrylhydrazyl (DPPH) scavenging activity and ferric reducing antioxidant potential (FRAP) of ethanol extract of Jatropha tanjorensis leaves was evaluated according to the methods of Alam et al. (2013) and Oyaizu (1986) respectively.

\section{Statistical analysis}

Three analytical determinations were carried out on each independent replication for every parameter. Statistical analyses were performed by one-way analysis of variance, followed by turkey test. Significance value was set at $P<0.05$ using graph pad prism 6 .

\section{Results}

Extract yield

The yield of the crude ethanol extract of Jatropha tanjorensis leaves after concentration and drying was $10.1 \mathrm{~g}$ (7.3\%).

\section{GC-Ms analysis of ethanolic extract of Jatropha tanjorensis} leaves

Table 1 and Fig. 1 show the result of GC-MS analysis of ethanol extract of $J$. tanjorensis leaves. The result revealed the presence of 8 compounds from 11 chromatogram peak. Compounds detected comprise some different classes of hydrocarbons, alcohols, steroidal compounds, fatty acids and their derivatives.

Table 1 List of compounds identified at various retention times (RT) from ethanolic extract of Jatropha tanjorensis leaves by GCMS

\begin{tabular}{lllc}
\hline S/N & $\begin{array}{l}\text { Retention time } \\
\text { (Min) }\end{array}$ & Compounds name & $\begin{array}{l}\text { Peak area } \\
\text { ratio (\%) }\end{array}$ \\
\hline 1 & 12.363 & 3,4-dimethylcyclohexanol & 3.68 \\
2 & 12.741 & Hexadecanoic acid & 6.69 \\
3 & 13.434 & 1-cyclohexylnonene & 19.58 \\
4 & 13.485 & Phytol & 13.24 \\
5 & 13.662 & 2(1H)-Naphthalenone & 4.22 \\
6 & 13.685 & cyclopropyloctanoic acid & 5.55 \\
7 & 14.275 & Adipic acid & 4.23 \\
8 & 14.275 & propyl(4-((propoxycarbonyl) & 4.23 \\
\hline
\end{tabular}




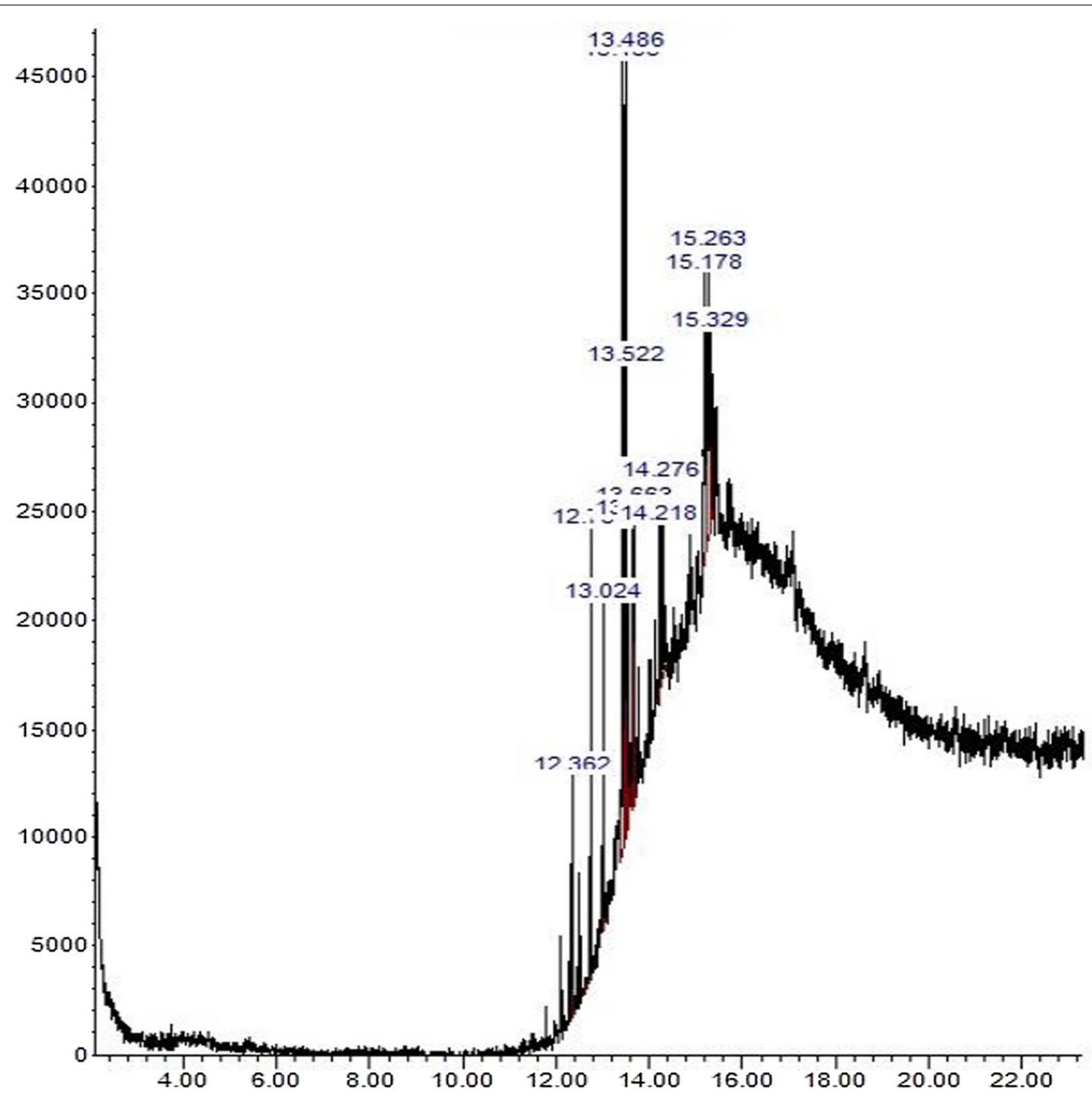

Fig. 1 Mass chromatogram of ethanolic extract of leaves of Jatropha tanjorensis

\section{ADME/toxicity screening and drug likeness prediction of compounds from ethanolic extract of Jatropha tanjorensis leaves}

From Table 2, all the eight compounds showed positive to blood brain barrier $(\mathrm{BBB}+)$, human intestinal absorption (HIA + ) and Caco-2 permeability (CAco$2+$ ) except adipic acid that was negative to Caco-2. The compounds revealed non-substrate and non-inhibitors of p-glycoprotein and CYP3A4. All the detected compounds were observed to be non-carcinogenic. It was observed that, the eight compounds have not violated more than one of the lipinski's rule of five (Table 3). The logkp reveals that adipic acid has the highest skin penetrating potential $(-5.95 \mathrm{~cm} / \mathrm{s})$.

\section{Molecular docking analysis}

As shown in Table 4. The standard drug (diclofenac) possesses binding affinity of $-8.81 \mathrm{kcal} / \mathrm{mol}$ with COX-1 and $-6.98 \mathrm{kcal} / \mathrm{mol}$ with COX-2. The binding affinities of all the compounds against COX-1 were observed to be lower compared to that of the reference drug. The interaction of hexadecanoic acid $(-7.66 \mathrm{kcal} / \mathrm{mol}), 1$-cyclohexylnonene $(-7.37 \mathrm{kcal} / \mathrm{mol})$ and cyclopropylactonoic acid $(-6.15 \mathrm{kcal} / \mathrm{mol})$ showed the highest binding affinity against COX-1 compared to other compounds while phytol $(-7.21 \mathrm{kcal} / \mathrm{mol})$, 1-cyclohexylnonene $(-6.97 \mathrm{kcal} /$ $\mathrm{mol})$ and 2(1H)-Naphthalenone revealed high binding affinities against COX-2. Phytol showed higher binding affinity compared to the standard drug. 
Table 2 In silico ADME toxicity screening of the compounds

\begin{tabular}{|c|c|c|c|c|c|c|c|}
\hline Compounds & BBB & HIA & Caco2 perm & p-gp substrate/inhibitor & $\begin{array}{l}\text { CYP3A4 } \\
\text { non-inhibitor }\end{array}$ & Carcinogenicity & AMES/ Toxicity \\
\hline 3,4-dimethylcyclohexanol & + & + & + & Non-substrate/non-inhibitor & Non-inhibitor & Non-carcinogens & Non-toxic \\
\hline Hexadecanoic acid & + & + & + & Non-substrate/non-inhibitor & Non-substrate/non-inhibitor & Non-carcinogens & Non-toxic \\
\hline 1-cyclohexylnonene & + & + & + & Non-substrate/non-inhibitor & Non-substrate/non-inhibitor & Non-carcinogens & Non-toxic \\
\hline Phytol & + & + & + & Non-substrate/non-inhibitor & Non-substrate/non-inhibitor & Non-carcinogens & Non-toxic \\
\hline 2(1H)-Naphthalenone & + & + & + & Non-substrate/non-inhibitor & Non-substrate/non-inhibitor & Non-carcinogens & Toxic \\
\hline cyclopropyloctanoic acid & + & + & + & Non-substrate/non-inhibitor & Non-substrate/non-inhibitor & Non-carcinogens & Non-toxic \\
\hline Adipic acid & + & + & - & Non-substrate/non-inhibitor & Non-substrate/non-inhibitor & Non-carcinogens & Non-toxic \\
\hline $\begin{array}{l}\text { propyl(4- } \\
\text { ((propoxycarbonyl)oxy) } \\
\text { butyl)carbamate }\end{array}$ & + & + & + & Non-substrate/non-inhibitor & Non-substrate/non-inhibitor & Non-carcinogens & Non-toxic \\
\hline
\end{tabular}

BBB Blood Brain Barrier, HIA Human Intestinal Absorption, Caco-2 permeability P-glycoprotein substrate/ inhibitor; p-gp Substrate/Inhibitor, Cytochrome 3A4 Inhibition/Substrate, CYP3A4 Inhibition/Substrate

Table 3 In silico drug likeness prediction of the compounds

\begin{tabular}{|c|c|c|c|c|c|c|c|}
\hline Compounds & MW & HBA & HBD & TPSA & XLOGP & $\log K p(\mathrm{~cm} / \mathrm{s})$ & $\begin{array}{l}\text { Lipinski } \\
\text { Violation }\end{array}$ \\
\hline 3,4-dimethylcyclohexanol & 128.21 & 1 & 1 & 20.23 & 2.04 & -5.63 & 0 \\
\hline Hexadecanoic acid & 256.42 & 2 & 1 & 37.30 & 7.17 & -2.77 & 1 \\
\hline 1-cyclohexylnonene & 208.38 & 0 & 0 & 0 & 6.98 & -2.62 & 1 \\
\hline Phytol & 296.53 & 1 & 1 & 20.23 & 8.19 & -2.29 & 1 \\
\hline 2(1H)-Naphthalenone & 144.17 & 1 & 0 & 17.07 & 1.87 & -5.85 & 0 \\
\hline cyclopropyloctanoic acid & 184.28 & 1 & 01 & 37.30 & 4.00 & -4.58 & 0 \\
\hline Adipic acid & 261.31 & 5 & 1 & 73.86 & 2.74 & -5.95 & 0 \\
\hline $\begin{array}{l}\text { propyl(4-((propoxycarbonyl)oxy) } \\
\text { butyl)carbamate }\end{array}$ & 153.22 & 2 & 0 & 29.43 & 4.09 & -4.33 & 0 \\
\hline
\end{tabular}

$M W$ molecular weight ( $<500), H B A$ number of hydrogen bond acceptors $(<10), H B D$ number of hydrogen bond donor $(<5)$, XlogP the partition coefficient $\leq 5, T P S A$ topological polar surface area

Table 4 Docking score of compounds

\begin{tabular}{lll}
\hline Compounds Name & \multicolumn{2}{l}{ Binding Affinity (kcal/mol) } \\
\cline { 2 - 3 } & COX-1 & COX-2 \\
\hline 3,4-dimethylcyclohexanol & -4.90 & -6.23 \\
Hexadecanoic acid & -7.66 & -5.64 \\
1-cyclohexylnonene & -7.37 & -6.97 \\
phytol & -6.10 & -7.21 \\
2(1H)-Naphthalenone & -6.02 & -6.33 \\
cyclopropyloctanoic acid & -6.15 & -3.61 \\
Adipic acid & -4.48 & -4.14 \\
propyl(4-((propoxycarbonyl)oxy)butyl) & -3.77 & -4.03 \\
carbamate & & -6.98 \\
Diclofenac & -8.81 & \\
\hline
\end{tabular}

COX-1 cyclooxygenase-1, COX-2 cyclooxygenase-2

These compounds interacted with various amino acids by conventional hydrogen bonds, pi-pi stacking etc. at the same binding pocket of the target proteins as shown in Figs. 2a, b and 3a, b.

\section{Molecular Mechanics/generalized born surface area (MM/ GBSA) analysis}

MM/GBSA of the protein-ligand complexes were calculated for reliability and accuracy in computing energy (Fig. 4). The result presented in Fig. 5a, b revealed that $2(1 \mathrm{H})$-naphthalenone, cyclopropylactanoic acid, adipic acid and propyl(4-(propoxycarbonyl)oxy)butylcarbamate posse higher MM/GBSA binding energy compared to the standard drug (diclofenac) against COX-1 while adipic acid and cyclopropylactanoic acid showed lower MM/GBSA binding energy against COX-2 compared to the standard drug.

97960: 3,4-dimethylcyclohexanol; 985: Hexadecanoic acid; 5364533: 1-cyclohexylnonene; 5280435: Phytol; 11400841: 2(1H)-Naphthalenone; 57346156: Cyclopropylactanoic acid; 196: Adipic acid; 91713661: propyl(4-((propoxycarbonyl)oxy)butylcarbamate; 3033: Diclofanac. 


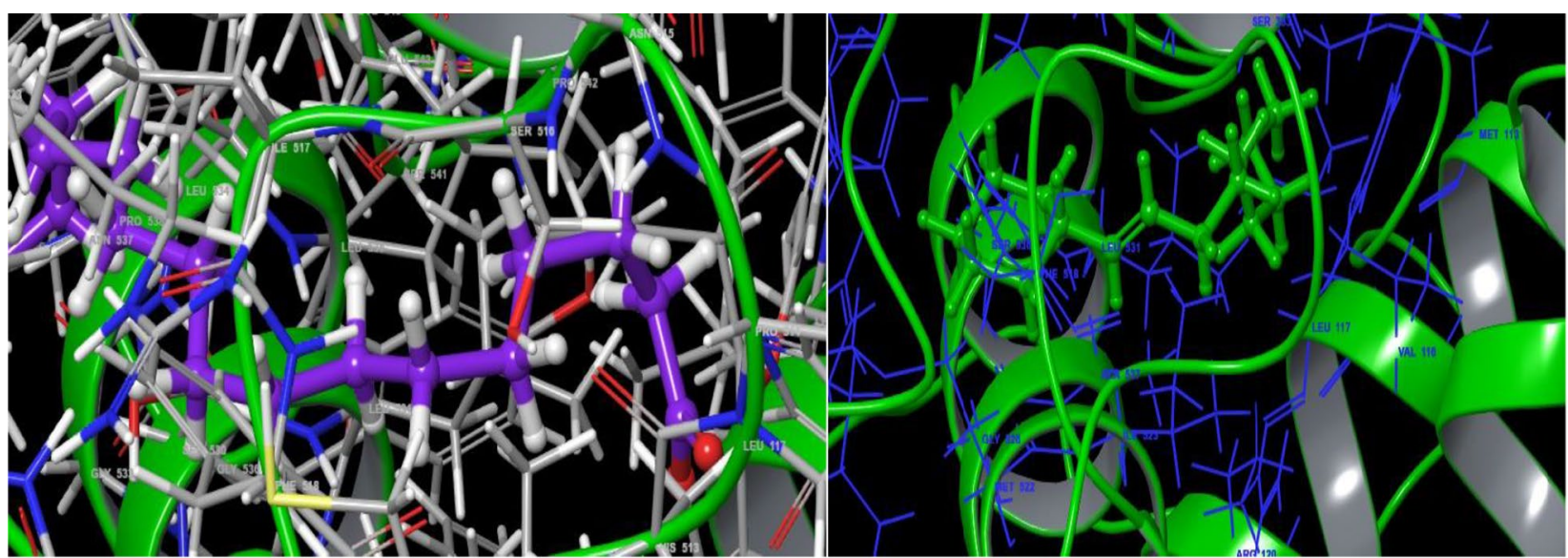

(a)

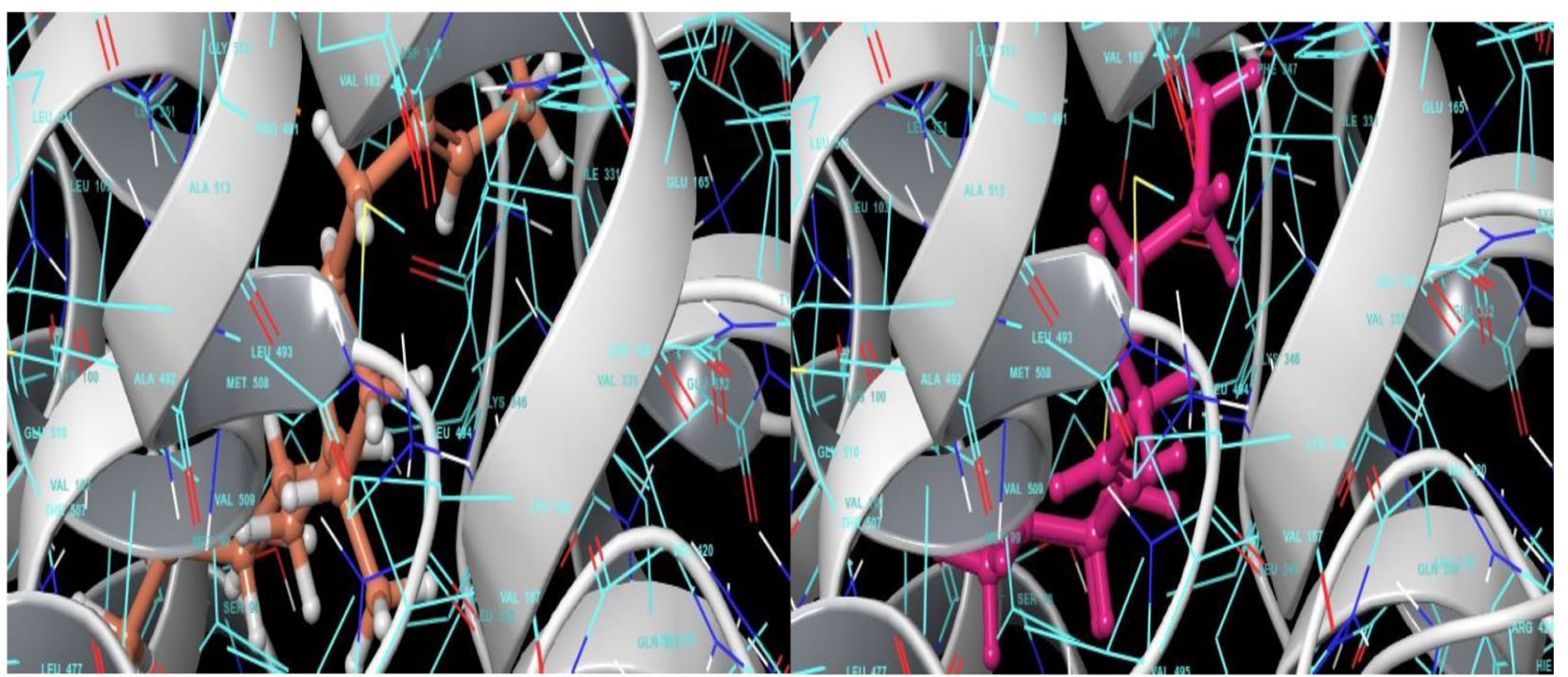

(b)

Fig. 2 (a) Interactions of compounds with the highest affinity with the active site amino acids of the target (a) COX 1-Hexadecanoic acid (b) COX1-1-cyclohexylnonene, $\mathbf{b}$ Interactions of compounds with the highest affinity with the active site amino acids of the target (a) COX 2-Pytol (b) cox 2-1-cyclohexylnonene

In vitro antioxidant effect of ethanol extract of $J$.

\section{tanjorensis leaf}

The ethanol extract of $J$. tanjorensis leaf showed highest DPPH scavenging activity at $1000 \mu \mathrm{g} / \mathrm{ml}$. The DPPH scavenging capacity of the extract across the concentration were observed to be lower compared to the standard (garlic acid) as shown in Fig. 6a. The ferric reducing antioxidant power (FRAP) of the extract was significantly $(P<0.05)$ higher at concentration of $50 \mu \mathrm{g} / \mathrm{ml}$. the extract shows appreciable antioxidant power but at concentration of $100 \mu \mathrm{g} / \mathrm{ml}$, the antioxidant power significantly $(P<0.05)$ reduced (Fig. $6 b)$.
In vitro anti-inflammatory effect of ethanol extract of $J$. tanjorensis leaf

Figure $7 \mathrm{a}$ shows the percentage inhibition of hypotonicity induced haemolysis of ethanol extract of $J$. tanjorensis leaf. The extract at concentration of $200 \mu \mathrm{g} / \mathrm{ml}$ showed significant $(P<0.05)$ reduction in percentage inhibition of haemolysis compared to the standard drug (diclofenac sodium). The percentage inhibition of haemolysis observed at 600 and $1000 \mu \mathrm{g} / \mathrm{ml}$ concentration of the extract were non-significantly $(P>0.05)$ higher compared to the standard drug. 


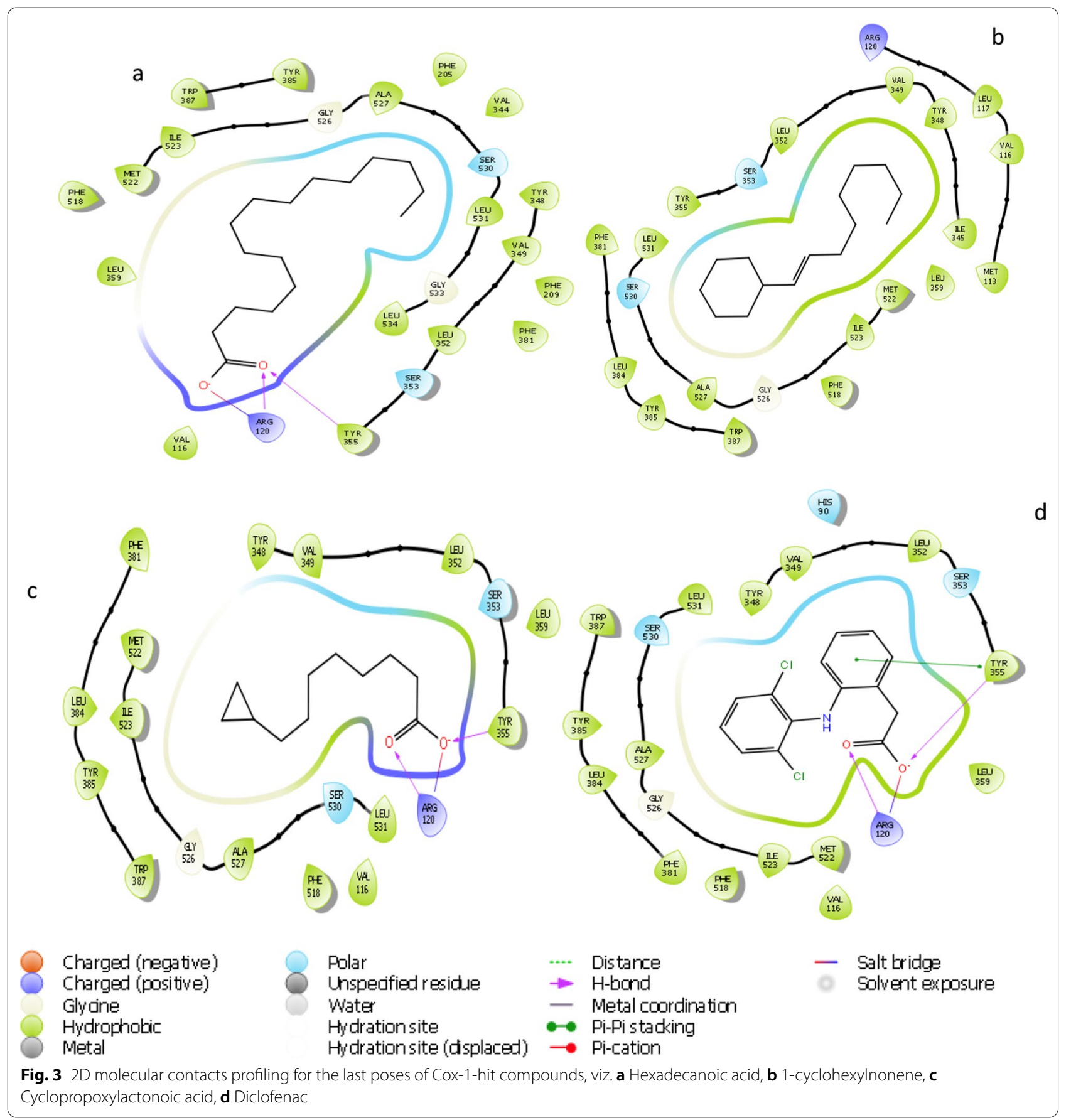

As shown in Fig. 7b, the percentage inhibition of albumin denaturation of ethanol extract of $J$. tanjorensis leaf at 25 and $50 \mu \mathrm{g} / \mathrm{ml}$ were significantly $(P<0.05)$ higher compared to diclofenac sodium. The percentage inhibition of the extract at $200 \mu \mathrm{g} / \mathrm{ml}$ was significantly $(P<0.05)$ reduced compared to diclofenac sodium.

\section{Discussion}

GC-MS is suitable for the identification and quantification of sterols moieties at ambient temperature due to its stable nature (Chen et al. 2015). Table 1 and Fig. 1 showed the result of GC-MS analysis of ethanol extract of $J$. tanjorensis leaf. The result revealed the presence of 


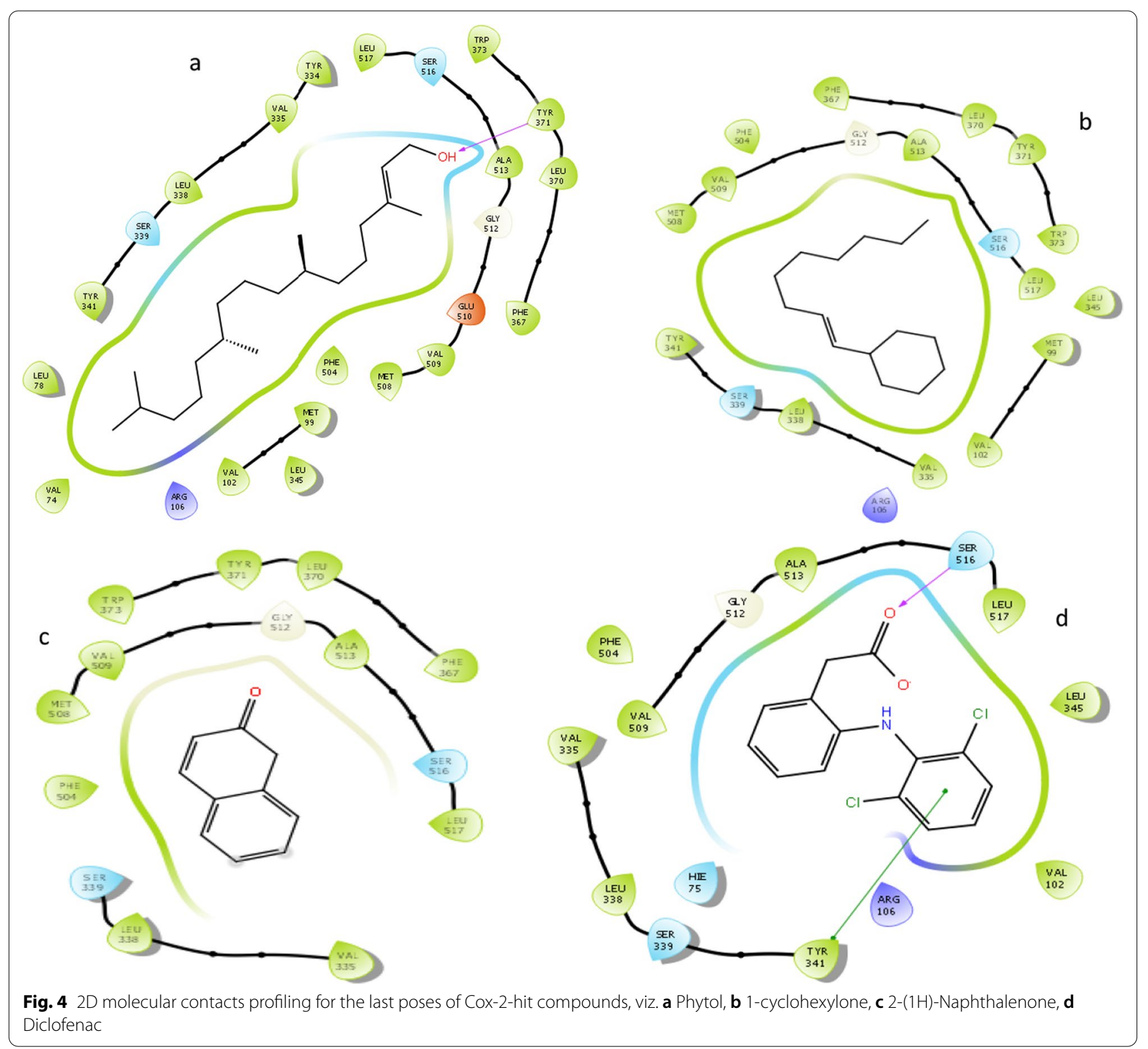

eight (8) compounds; these compounds detected comprise some different classes of hydrocarbons, alcohols, steroidal compounds, fatty acids and their derivatives. The presence of eicosanoic acid, methyl esters, heneicosanoic acid and fatty acid derivatives revealed by GC-MS possess many physiological and biochemical functions (Eseyin et al. 2018).

The pharmacokinetics and pharmacodynamics profiles of the eight compounds from GC-MS analysis of ethanol extract of $J$. tanjorensis leaf were predicted by absorption, distribution, metabolism, excretion, toxicity and drug likeness prediction, the results were presented in Tables 2 and 3.
From Table 2, all the compounds were positive to human intestinal absorption (HIA), which implies that they can be easily absorbed into the blood stream. All the compounds can also cross the blood brain barrier $(\mathrm{BBB}+)$. Blood brain barrier is the regulated interface between the peripheral circulation and the central nervous system (Hawkins and Davis 2005). The failure of many therapeutic molecules as drug candidates has been attributed to their inability to cross the barrier between the blood and the brain (Ballabh et al. 2004). Therefore, it is worthy to note that, all the compounds can cross the $\mathrm{BBB}$. The result agreed with the findings of Akinloye et al. (2020) who reported that phytosterols from Nicotiana 



5280435

3033

5364533

11400841

- 97960

985

91713661

196

57346156

Fig. 5 a Graphical representation of the and Prime/MM-GBSA binding energy ( $\Delta G_{\text {bind }}$ ) of COX 1-Ligand Complex, $\mathbf{b}$ Graphical representation of the and Prime/MM-GBSA binding energy $\left(\triangle G_{\text {bind }}\right)$ of COX 2-Ligand Complex

tabacum can cross the BBB. All the compounds were positive to colon cancer carcinoma cell line (Caco2) except adipic acid, this indicates that most of the compounds can penetrate the intestine.

The compounds showed non-substrate and non-inhibitor of p-glycoprotein (p-gp). P-gp is an efflux membrane transporter; one of the first members of the ATP-binding cassette $(\mathrm{ABC})$ transported acting as a physiological barrier by extruding drugs out of the cell (Amin 2013). All the compounds are good drug molecules showing non-substrate and non-inhibitor of p-gp. CYP 3A4 is often considered the most important drug-metabolizing 

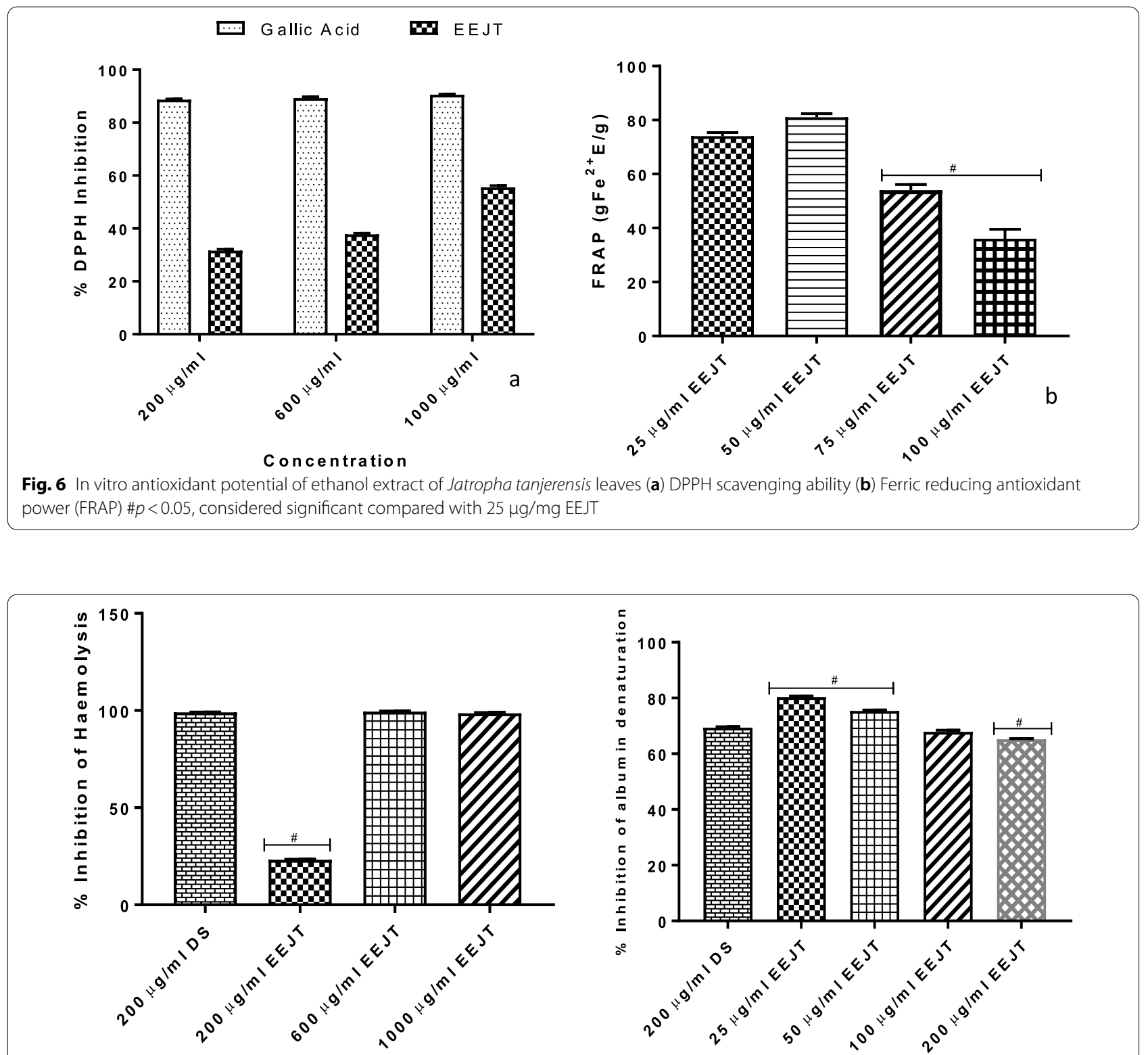

Fig. 7 In vitro anti-inflammatory potential of ethanol extract of Jatropha tanjerensis leaves (a) hypotonicity induced haemolysis of erythrocyte (b) Albumin denaturation. ${ }^{\sharp} P<0.05$, significant compared to $200 \mu \mathrm{g} / \mathrm{ml}$ of Diclofenac sodium (DS)

enzyme, due to its relative expression in the liver and intestine (Tirona and Kim 2017). It oxidizes small foreign organic molecules such as drug for removal from the body. The tendency of drug molecules to interact with CYP 3A4 is associated with adverse side effects (Zhou 2008). All the compounds are non-substrate and non-inhibitor of CYP 3A4 therefore, side effects or drugdrug interactions will be very low or absent. Increasing numbers of carcinogens and promoters of carcinogenesis are being found in natural plants products (Bednar and Linsmaier-Bednar 1989). Drug likeness is a complex balance of various molecular properties and structural features which determines a particular molecule as drug or non-drug (Turner and Agatonovic-Kustrin 2007). In doing so, Lipinsk's rule of five is followed according to Lipinski et al. (2001). The rule state that drug like compounds should not violate more than one of the rules. There is poor absorption or permeation when molecular weight $(\mathrm{MW})$ is greater than $500 \mathrm{KD}$ and calculated $\operatorname{LogP}$ is greater than 5 , there are more than five hydrogen bond donors (HBD) and the number of hydrogen bond acceptor is greater than 10. It is interesting that, the 
compounds (Table 3) have not violated more than one of the lipinsk's rule of five which predict the compounds as drug-like candidates. The in vitro method of prediction of skin permeability has been reported as human skin permeability coefficient (Logkp) (Scheler et al. 2015). The logkp values of the compounds (Table 3) show that adipic acid has the highest permeability coefficient $(-5.95 \mathrm{~cm} / \mathrm{s})$ compared to other compounds.

The bioactive compounds from J. tanjorensis showed a favorable binding affinity and optimally saturated the active site of cyclooxygenase-1, ranging from hexadecanoic acid to 1-cyclohexylnonene with the binding energy of -7.66 and $-7.37 \mathrm{kcal} / \mathrm{mol}$ respectively. The interaction of these compounds against cyclooxygenase- 2 active site showed binding affinity of -7.21 and $-6.97 \mathrm{kcal} / \mathrm{mol}$ for phytol and $2(1 \mathrm{H})$-Naphthalenone respectively.

Following the docking approach, the lead compounds (hexadecanoic acid) bind firmly within the active site of COX-1 forming three hydrogen bonds with the amino acid residues: ARG 120 and TYR 355. The lead compound (phytol) interacted with COX-2 by forming one hydrogen bond with TYR 371 at the binding site of the protein (Fig. 3).

The MM/GBSA $\left(\Delta G^{\text {bind }}\right)$ for COX1/COX2-hit ligand complexes were calculated using the MM/GBSA module integrated with the prime program of the Schrodinger suite. MM/GBSA has been widely involve in bio-molecular studies such as protein folding, protein-ligand binding, protein-protein interaction etc. it is arguably very popular method for free energy prediction since they are more accurate than most scoring functions of molecular docking and less computationally demanding (Wang et al. 2019). The $\Delta G^{\text {bind }}$ was utilized for advanced mechanics calculation of the binding energy for the screened compounds following the docking analysis. Based on the MM-GBSA output (Fig. 5), 2(1H)-Naphthalenone, Cyclopropylactanoic acid, Adipic acid, propyl(4((propoxycarbonyl)oxy)butylcarbamate complexes with COX 1 demonstrated $\Delta G^{\text {bind }}$ of $-30.07,-27.43,-24.79$, and $-24.66, \mathrm{kcal} / \mathrm{mol}$, respectively (Fig. 5a). Diclofenac had the $\Delta G^{\text {bind }}$ of $-22.88 \mathrm{kcal} / \mathrm{mol}$. Hence, the $\Delta G^{\text {bind }}$ results further ascertain that $J$. tanjorensis compounds bind better compared to the positive control ligand (diclofenac).

The in vitro antioxidant activities of ethanol extract of $J$. tanjorensis leaf are presented in Fig. 6. The percentage inhibition of 1,1-diphenyl-2-picrylhydrazyl (DPPH) scavenging activity increase with increase in the extract concentration. The highest inhibitory activity was observed at $1000 \mu \mathrm{g} / \mathrm{ml}$. The effect of antioxidant $\mathrm{DPPH}$ is due to their hydrogen donating ability (Ashafa et al. 2010). FRAP assay evaluates the reducing power of antioxidant interaction with ferric-tripyridyltriazine complex. Donation of hydrogen atom contributes to the breaking of the free radical chain (Rajurkar and Hande 2011). The ferric reducing antioxidant potential (FRAP) of ethanol extract of $J$. tanjorensis leaf revealed concentration dependent decrease in FRAP activity. The highest FRAP activity was observed at low concentration of $25 \mu \mathrm{g} / \mathrm{ml}$. the $\mathrm{IC}_{50}$ of DPPH and FRAP were 136.129 and $4.43 \mathrm{gFe}^{2+} \mathrm{E} / \mathrm{g}$ respectively. Oxidative stress enhances pro-inflammatory cytokines production (Karigidi et al. 2020). Hence, the free radical scavenging potential of $J$. tanjorensis leaf through antioxidant production might enhance their anti-inflammatory property.

Red blood cell (RBC) membrane stabilization was employed to study anti-inflammatory potential of $J$. tanjorensis because RBC resembles lysosomes in terms of the membrane similarity (Chou 1997). Hypotonicity induced haemolysis could result from shrinkage of the cells due to osmotic loss of electrolytes (Parvin et al. 2015). The ethanol extract of $J$. tanjorensis leaf at 600 and $1000 \mu \mathrm{g} / \mathrm{ml}$ effectively inhibit hypotonicity induced hemolysis. The percentage inhibition of hemolysis of the extract at $200 \mu \mathrm{g} / \mathrm{ml}$ was significantly $(P<0.05)$ reduced compared to diclofenac sodium at $200 \mu \mathrm{g} /$ $\mathrm{ml}$. At concentration of 600 and $1000 \mu \mathrm{g} / \mathrm{ml}$ of the extract, the percentage albumin denaturation inhibition was non-significantly $(P>0.05)$ higher compared to diclofenac at $200 \mu \mathrm{g} / \mathrm{ml}$ as shown in Fig. 7a. This result demonstrated that $J$. tanjorensis could possess antiinflammatory potential. Previous studies have reported that, plants with anti-inflammatory potential have the capacity to stabilize cell membrane against hemolysis (Anyasor et al. 2019; Chamlagai and Singh 2016). The result obtained in this study is consistent with the findings of Arun and Brindha (2012) who reported effective membrane stabilization of $J$. tanjorensis leaf extract at 100 and $250 \mu \mathrm{g} / \mathrm{ml}$.

Denaturation of protein is a biochemical reaction that occurs as a result chronic inflammatory reaction resulting into loss of tissue functions (Sangeetha and Vidhya 2016). It is well documented as one of the causes of inflammation (Govindappa et al. 2011). One of the mechanisms of NSAIDs action is inhibition of protein denaturation (Gunathilake et al. 2018). Figure 7b shows that, ethanol extract of $J$. tanjorensis significantly $(P<0.05)$ increase percentage inhibition of albumin denaturation at 25 and $50 \mu \mathrm{g} / \mathrm{ml}$ compared to $200 \mu \mathrm{g} / \mathrm{ml}$ of diclofenac sodium. The extract shows significant $(P<0.05)$ reduction in percentage albumin denaturation inhibition at $200 \mu \mathrm{g} /$ $\mathrm{ml}$ compared to diclofenac sodium at $200 \mu \mathrm{g} / \mathrm{ml}$. The percentage inhibition of albumin denaturation observed in this study is consistent with the findings of Arun and Brindha (2012) who reported high percentage inhibition at 100 and $250 \mu \mathrm{g} / \mathrm{ml}$ of $J$. tanjorensis leaf. 


\section{Conclusions}

This study was conducted to identify the bioactive compounds present in J. tanjorensis leaves using GC-MS as potent inhibitors of COX-1 and COX-2 by employing structure-based drug design techniques. After the computational analysis via molecular docking and MM/GBSA quantum chemical calculations, J. tanjorensis ligands exhibited higher binding energy and favorable intermolecular interactions in the binding pocket of COX-1 and COX-2 in comparison to the reference ligand (diclofenac).

Furthermore, in vitro antioxidant and anti-inflammatory assay revealed $J$. tanjorensis leaves possess good percentage DPPH inhibition and ferric reducing antioxidant power. The percentage inhibition of heamolysis and albumin denaturation was comparable to the reference drug (diclofenac) which shows that J. tanjoresis leaves might be a good source of antioxidant and antiinflammatory agent, however further in vivo investigation is required to validate the result from this study.

\begin{abstract}
Abbreviations
JT: Jatropha tanrogenesis; GC-MS: Gas chromatography-mass spectrometry: COX-1: Cyclooxygenase-1; COX-2: Cyclooxyganse-2; DPPH: 1,1 Diphenyl-2-picrylhydrazyl; FRAP: Ferric reducing antioxidant potential; ADME: Absorption, distribution, metabolism, and excretion; NSAID: Non-steroidal anti-inflammatory drugs; GIT: Gastro-intestinal tract; PDB: Protein data bank; SDF: Structuredata file; 3D: 3-Dimenssional; RMSD: Root mean square deviation; OPLS: Optimized potentials for liquid simulations; XP: Extra precision; MM/GBSA: Molecular mechanics/generalized born surface area; BBB: Blood Brain Barrier; HIA: Human Intestinal Absorption; MW: Molecular weight; HBA: Hydrogen bond acceptors; HBD: Hydrogen bond donor; XlogP3: Partition coefficient; TPSA: Topological polar surface area.
\end{abstract}

\section{Acknowledgements}

The author sincerely acknowledges Dr. Omotuyi I. O. of the Department of Biochemistry, Adekunle Ajasin University for providing the Maestro Schrödinger software utilized in the computational study.

\section{Authors' contributions}

DAO performed all the computational analysis and wrote the manuscript.

\section{Funding}

No funding was received by the author for this research.

No funding was received by the author for this research.

\section{Availability of data and materials}

Not applicable.

\section{Declarations}

Ethics approval and consent to participate

Not applicable.

\section{Consent of publication}

Not applicable.

\section{Competing interests}

The correspondents did not acknowledge competing of interest.
Received: 27 October 2021 Accepted: 7 November 2021

Published online: 14 November 2021

\section{References}

Akinloye OA, Akinloye DI, Onigbinde SB, Metibemu DS (2020) Phytosterols demonstrate selective inhibition of COX-2: In-vivo and in-silico studies of Nicotiana tabacum. Bioorganic Chem 102:104037

Alam MN, Bristi NJ, Rafiquzzaman M (2013) Review on in vivo and in vitro methods evaluation of antioxidant activity. Saudi Pharmaceut J 21:143-152

Amin L (2013) P-glycoprotein inhibition for optimal drug delivery. Drug Target Insights 7:27-34

Anyasor GN, Okanlawon AA, Ogunbiyi B (2019) Evaluation of anti-inflammatory activity of Justicia secunda Vahl leaf extract using in vitro and in vivo inflammation models. Clin Phytoscience 5:1-13

Arun KP, Brindha P (2012) Studies on antioxidant and antiarthritic potentials of Jatropha tanjorensis Ellis and Saroja. Int J Pharm Pharm Sci 4:136-138

Ashafa AOT, Grierson DS, Afolayan AJ (2010) In vitro antioxidant activity of extracts from the leaves of Felicia muricata thunb. An underutilized medicinal plant in the eastern cape province, South Africa. Afr J Tradit Complement Altern Med 7(4):296-302

Attiq A, Jalil J, Husain K, Ahmad W (2018) Raging the war against inflammation with natural products. Front Pharmacol 9:976

Azeem AK, Dilip C, Prasanth SS, Junise V, Hanan S (2010) Anti-inflammatory activity of the glandular extracts of Thunnus alalunga. Asia Pac J Med 3(10):412-420

Ballabh P, Braun A, Nedergaard M (2004) The blood-brain barrier: an overview: structure, regulation, and clinical implications. Neurobiol Dis 16:1-13

Balogun TA, labal MN, Saibu OA, Akintubosun MO, Lateef OM, Nneka UC, Abdullateef OT, Omoboyowa DA (2021) Discovery of potential HER2 inhibitors from Mangifera indica for the treatment of HER2-Positive breast cancer: an integrated computational approach. J Biomol Struct Dyn. https://doi.org/10.1080/07391102.2021.1975570

Bednar TW, Linsmaier-Bednar EM (1989) Chemical carcinogens in plants and interaction with viruses and cancer causation. In: Kaiser HE (eds) Comparative aspects of tumor development. Cancer growth and progression, vol 5. Springer, Dordrecht. https://doi.org/10.1007/978-94-009-1091-1_29

Bouhlali EDT, Alem C, Zegzouti YF (2016) Antioxidant and anti-hemolytic activities of phenolic constituents of six moroccan date fruit (Phoenix dactylifera L.) syrups. Biotechnol Indian J 12(1):45-52

Chamlagai D, Singh B (2016) Study of in vitro anti-inflammatory activity of ethnomedicinal plants of Sikkim Viscum Articulatum and Acorus Calamus. Asian J Pharm Clin Res 9(3):119-122

Chen YZ, Kao SY, Jian HC, Yu YM, Li JY, Wang WH, Tsai CW (2015) Determination of cholesterol and four phytosterols in foods without derivatization by gas chromatography-tandem mass spectrometry. J Food Drug Anal 23(4):636-644

Cheng F, Li W, Zhou Y, Shen J, Wu Z, Liu G, Lee PW, Tang Y (2012) admetSAR: a comprehensive source and free tool for evaluating chemical ADMET properties. J Chem Inf Mode 52(11):3099-3105

Chou CT (1997) The anti-inflammatory effect of Tripterygium wilfordi Hook on adjuvant induced paw edema in rats and inflammatory mediator's release. Phytother Res 17:152-154

Daina A, Michielin O, Zoete V (2017) Swiss ADME: A free web tool to evaluate pharmacokinetics, drug-likeness and medicinal chemistry friendliness of small molecules. Sci Rep 7:42717

Erukainure OL, Hafizur RM, Kabir N, Choudhary MI, Atolani O, Banerjee P, Preissner R, Chukwuma Cl, Muhammad A, Amonsou EO, Islam MS (2018) Suppressive effects of Clerodendrum volubile P Beauv. [Labiatae] methanolic extract and its fractions on type 2 diabetes and its complications. Front Pharmacol 9:8

Eseyin OA, Sattar MA, Rathore HA, Aigbe F, Afzal S, Ahmed A, Lazhari M, Akthar $S$ (2018) GC-MS and HPLC profiles of phenolic fractions of the leaf of Telfairia occidentalis. Pak J Pharm Sci 31(1):45-50

Friesner RA, Murphy RB, Repasky MP, Frye LL, Greenwood JR, Halgren TA, Sanschagrin PC, Mainz DT (2006) Extra precision glide: Docking and scoring incorporating a model of hydrophobic enclosure for protein-ligand 
complexes. J Med Chem 49(21):6177-6196. https://doi.org/10.1021/ jm0512560

Govindappa M, Naga SS, Poojashri MN, Sadananda TS, Chandrappa CP (2011) Antimicrobial, antioxidant and in vitro anti-inflammatory activity of ethanol extract and active phytochemical screening of Wedelia trilobata (L.) Hitchc. J Pharmacogn Phytotherapy. 3(3):43-51

Gunathilake K, Ranaweera K, Rupasinghe H (2018) In vitro anti-inflammatory properties of selected green leafy vegetables. Biomed 6(4):107

Hawkins BT, Davis TP (2005) The blood brain barrier/neurovascular unit in health and disease. Pharmacol Rev 57(2):273-185

Karigidi KO, Akintimehin ES, Omoboyowa DA, Adetuyi FO, Olaiya CO (2020) Effect of Curculigo pilosa supplemented diet on blood sugar, lipid metabolism, hepatic oxidative stress and carbohydrate metabolism enzymes in streptozotocin-induced diabetic rats. J Diabetes Metab Disord. https://doi.org/10.1007/s40200-020-00618-w

Leelaprakash G, Mohan-Dass S (2011) In vitro anti-inflammatory activity of methanol extract of Enicostemma Axillare. Int J Drug Dev Res 3(3):189-196

Lipinski CA, Lombardo F, Dominy BW, Feeney PJ (2001) Experimental and computational approaches to estimate solubility and permeability in drug discovery and development settings. Adv Drug Deliv 46:3-26

Maestro (2018) Maestro. Schrodinger, LLC.

Nathan C, Ding A (2010) Nonresolving inflammation. Cell 140:871-882

Ochulor OC, Njoku OU, Uroko RI, Egba SI (2018) Nutritional composition of Jatropha tanjorensis leaves and effects of its aqueous extract on carbon tetrachloride induced oxidative stress in male Wistar albino rats. Biomed Res 29(19):3569-3576

Oguntibeju OO (2018) Medicinal plants with anti-inflammatory activities from selected countries and regions of Africa. J Inflamm Res 11:307-331

Okereke SC, Arunsi UO, Nosiri Cl, Nwadike C (2017) Gas chromatography mass spectrometry/fourier transform infrared (GC-MS/FTIR) spectral analysis of Tithonia diversifolia (Hemsl.) A. Gray leaves. J Med Plants Res 11(19):345-350

Olayiwola G, Iwalewa EO, Omobuwajo OR, Adebayo AL, Adeniyi AA, Verspohi EJ (2004) The antidiabtes potential of Jathropha tanjorensis leaves. Nig J Nat Prod Med 8:55-58

Omoboyowa DA, Balogun TA, Omomule OM, Saibu OA (2021) Identification of terpenoids from Abrus precatorius against Parkinson's disease protein using in silico approach. Bioinfomatics Biology Insight 15:1-8

Omoregie ES, Osagie AU (2011) Effect of Jatropha tanjorensis leaves supplement on the activities of some antioxidant enzymes, vitamins and lipid peroxidation in rats. J Food Biochem 35(2):409-424

Orhue ES, Idu M, Ataman JE, Ebite LE (2008) Hematological and histopathological studies of Jatropha tanjorensis leave in Rabbits. Asian J Biol Sci 1:84-89
Oyaizu M (1986) Studies of products of browning reaction: antioxidative activity of products of browning reaction prepared from Glucosamine. Jpn J Nutr 44:307-315

Parvin S, Das N, Jahan N, Akhter A, Nahar L, Islam E (2015) Evaluation of in vitro anti-inflammatory and antibacterial potential of Crescentia cujete leaves and stem bark. BMC Res Notes 8:412-419

Prime. (2019). Prime. Schrodinger, LLC.

Rajurkar NS, Hande SM (2011) Estimation of phytochemical content and antioxidant activity of some selected traditional Indian medicinal plants. Indian J Pharm Sci 73(2):146-151

Roos K, Wu C, Damm W, Reboul M, Stevenson JM, Lu C, Dahlgren MK, Mondal S, Chen W, Wang L, Abel R, Friesner RA, Harder ED (2019) OPLS3e: extending force field coverage for drug-like small molecules. J Chem Theory Comp 15(3):1863-1874. https://doi.org/10.1021/acs.jctc.8b01026

Sangeetha G, Vidhya R (2016) In vitro anti-inflammatory activity of different parts of Pedalium murex (L.). Int J Herb Med 4(3):31-6

Sastry GM, Adzhigirey M, Day T, Annabhimoju R, Sherman W (2013) Protein and ligand preparation: parameters, protocols, and influence on virtual screening enrichments. J Computer-Aided Mol Des 27(3):221-234. https://doi.org/10.1007/s10822-013-9644-8

Scheler S, Fahr A, Liu X (2015) Linear combination methods for prediction of drug skin permeation. ADMET \& DMPK 2(4) 199-220

Tirona RG, Kim RB (2017) Introduction to clinical pharmacology In: Clinical and translational science ( $2^{\text {nd }}$ Edn): Academic press. USA, pp 365-388

Turner JV, Agatonovic-kustrin S (2007) In silico prediction of oral bioavailability. In: comprehensive medicinal chemistry II. 5: 699-724

Wang E, Sun H, Wang J, Wang Z, Liu H, Zhang JZH, Hou T (2019) End-point binding free energy calculation with MM/PBSA and MM/GBSA: Strategies and application in drug design. Chem Rev 119:9478-9508

Williams CS, Mann M, Dubois RN (1999) The role of cyclooxygenases in inflammation, cancer, and development. Oncogene 18(55):7908-7916

Yesmin S, Paul A, NazT, Rahman A, Akhter SF, Wahed MI, Emran TB, Siddiqui SA (2020) Membrane stabilization as a mechanism of the anti-inflammatory activity of ethanolic root extract of Choi (Piper chaba). Clin Phytoscience $6: 1-10$

Zhou S (2008) Drugs behave as substrates, inhibitors and inducers of human cytochrome P450 3A4. Curr Drug Metab 9:310

\section{Publisher's Note}

Springer Nature remains neutral with regard to jurisdictional claims in published maps and institutional affiliations.

\section{Submit your manuscript to a SpringerOpen ${ }^{\circ}$ journal and benefit from:}

- Convenient online submission

- Rigorous peer review

- Open access: articles freely available online

- High visibility within the field

- Retaining the copyright to your article

Submit your next manuscript at $\boldsymbol{\nabla}$ springeropen.com 